\title{
Correction to: Dying with SARS-CoV-2 infection-an autopsy study of the first consecutive 80 cases in Hamburg, Germany
}

\author{
Carolin Edler ${ }^{1}$ • Ann Sophie Schröder ${ }^{1}$ - Martin Aepfelbacher ${ }^{3}$ - Antonia Fitzek ${ }^{1} \cdot$ Axel Heinemann $^{1} \cdot$ Fabian Heinrich $^{1}$. \\ Anke Klein ${ }^{1} \cdot$ Felicia Langenwalder $^{1} \cdot$ Marc Lütgehetmann $^{3} \cdot$ Kira Meißner $^{1} \cdot$ Klaus Püschel $^{1} \cdot$ Julia Schädler $^{1}$. \\ Stefan Steurer ${ }^{2} \cdot$ Herbert Mushumba $^{1} \cdot$ Jan-Peter Sperhake ${ }^{1}$
}

Published online: 19 June 2020

(C) Springer-Verlag GmbH Germany, part of Springer Nature 2020

Correction to: International Journal of Legal Medicine (2020) https://doi.org/10.1007/s00414-020-02317-w

The affiliation of the author Martin Aepfelbacher was incorrectly assigned in the manuscript. Martin Aepfelbacher is affiliated to the Institute of Microbiology, University Medical Center Hamburg-Eppendorf, Hamburg, Germany, instead.

Publisher's note Springer Nature remains neutral with regard to jurisdictional claims in published maps and institutional affiliations.

The online version of the original article can be found at https://doi.org/ 10.1007/s00414-020-02317-w

\footnotetext{
Jan-Peter Sperhake

sperhake@uke.de

1 Department of Legal Medicine, University Medical Center Hamburg-Eppendorf, Butenfeld 34, 22529 Hamburg, Germany

2 Department of Pathology, University Medical Center Hamburg-Eppendorf, Hamburg, Germany

3 Institute of Microbiology, University Medical Center Hamburg-Eppendorf, Hamburg, Germany
} 